\title{
Do natural antioxidants play a role in Alzheimer's disease?
}

\author{
Klaus W. Lange ${ }^{a^{*}}$, Katharina M. Lange ${ }^{a}$, Yukiko Nakamura ${ }^{a}$ and Shiming Li ${ }^{b}$ \\ aDepartment of Experimental Psychology, University of Regensburg, Germany \\ ${ }^{b}$ Department of Food Science, Rutgers University, New Brunswick, NJ, USA \\ *Corresponding author: Klaus W. Lange, Institute of Psychology, University of Regensburg, 93040 Regensburg, Germany. Tel: +49941 \\ 9433815; Fax: +49 941 9434496; E-mail: klaus.lange@ur.de \\ DOI: $10.31665 /$ JFB.2020.11233 \\ Received: September 22, 2020; Revised received \& accepted: September 26, 2020 \\ Citation: Lange, K.W., Lange, K.M., Nakamura, Y., and Li, S. (2020). Do natural antioxidants play a role in Alzheimer's disease? J. Food \\ Bioact. 11: 2-10.
}

\begin{abstract}
Alzheimer's disease (AD) is a progressive neurodegenerative disorder characterized by globally impaired cognitive functions. Oxidative stress is involved in the formation of plaques and tangles, which damage neuronal cells in AD. Treatments retarding the progression of AD or significantly improving cognition are not available. Diet has been recognized as a modifiable lifestyle factor capable of affecting the risk of developing $A D$, since it may influence inflammation and oxidative stress in the brain. Dietary intake of natural antioxidants, such as polyphenols, carotenoids and vitamins $\mathrm{C}$ and $\mathrm{E}$, is thought to reduce oxidative stress and to have preventive or therapeutic potential in AD. Several antioxidants have shown promise in animal models of AD. However, there is no evidence of clinical efficacy of natural antioxidants in people with AD. The use of antioxidants may be hindered by their limited bioavailability. Furthermore, antioxidants administered in high concentrations could have detrimental effects due to their capacity to act as prooxidants. Potential effects of natural antioxidants in the prevention of AD should be assessed in studies with long-term exposure to compounds with high bioavailability. In addition, the assessment of the effectiveness of antioxidant-rich diets in AD deserves further investigation.
\end{abstract}

Keywords: Alzheimer's disease; Antioxidants; Oxidative stress; Prevention; Prooxidant activity.

\section{Introduction}

Alzheimer's disease (AD) is a progressive neurodegenerative disorder characterized by globally impaired cognitive functions, including memory, language, executive and other behavioral functions, and a marked decline in activities of daily life (Lange et al. 1995; Scheltens et al., 2016). AD is the most common form of dementia, occurring in approximately two thirds of affected individuals (Scheltens et al., 2016). The disease is characterized by neuronal and synaptic loss, and its neuropathological hallmarks are the extracellular deposition of misfolded amyloid- $\beta(A \beta)$ in senile plaques and the intracellular accumulation of hyperphosphorylated tau forms in neurofibrillary tangles (Butterfield and Lauderback, 2002; Crews and Masliah, 2010). The pathogenesis of $\mathrm{AD}$ is complex and incompletely understood. The accumulation of the neurotoxic $A \beta$ peptide in the brain appears to play a critical role in the pathophysiology of $\mathrm{AD}$, causing oxidative stress and neuroinflammation and ultimately leading to neuronal dysfunction and cell death (Butterfield and Lauderback 2002; Querfurth and LaFerla 2010). Disease-modifying therapies retarding the progression of $\mathrm{AD}$ or significantly improving cognitive functions in those affected by AD are currently not available (Scheltens et al. 2016).

$\mathrm{AD}$ has long been believed to be an inevitable consequence of aging. However, modifiable lifestyle behaviors are gaining increasing recognition as factors capable of affecting the risk of developing AD (Lange, 2018a; Sohn, 2018). In particular, diet and nutrition may play a role, since they can modulate brain structure and connectivity and affect cerebral and behavioral changes associated with aging and disease (Gustafson et al. 2015; Huhn et al. 2015). Nutritional approaches to AD include ketogenic diets targeting energetic deficits and reduced glucose utilization in AD (Lange et al., 2017), dietary patterns, such as the Mediterranean diet, with components that may beneficially affect pathophysi- 
ological processes of AD (Lange et al., 2019a), and medical foods meeting specific nutritional needs of people with neurodegenerative diseases (Lange et al., 2019b; Lange et al. 2019c).

\section{Oxidative stress in $A D$}

Reactive oxygen species (ROS), such as superoxide anion, hydrogen peroxide, hydroxyl radical, singlet oxygen, nitric oxide, alkoxyl and peroxyl radicals, are produced as a normal part of metabolism within the mitochondria (Sies, 1985). External factors promoting the production of free radicals include, for example, environmental pollutants, smoking, radiation and drugs. The endogenous antioxidant capacity is a multi-component system capable of neutralizing ROS to prevent damage of cellular compartments. A balance between the generation of ROS and the antioxidative defense system exists. In particular, the oxidation of unsaturated lipids in body tissues can be prevented effectively under normal conditions. Various enzymes, such as glutathione peroxidase and superoxide dismutase, are involved in the in vivo redox homeostasis and maintain intracellular ROS at low low levels (Sies, 1985). Oxidative stress in biological systems is characterized by an imbalance between the production of ROS and their removal by the antioxidant system (Harman, 1981; Sies, 1985), with an associated disruption of redox circuitry and macromolecular damage (Jones, 2006). The concentrations of ROS can exceed the removal capacity of the antioxidant system due to metabolic demand during aging or under pathological conditions. Excessive production and uncontrolled regulation of ROS can cause biological dysfunction (Yu, 1994; Dröge, 2002).

The brain is particularly prone to oxidative stress-induced damage due to its low antioxidant response capacity; it consumes around $20 \%$ of total body oxygen and contains high concentrations of polyunsaturated fatty acids subject to lipid peroxidation under conditions of high metabolic activity and oxygen utilization (Behl et al., 1994; Romero et al., 1998). The initiation of lipid peroxidation makes the brain a major target for neurodegeneration. ROS have been shown to act as secondary messengers in various intracellular signaling pathways and as mediators of inflammation and oxidative damage (Waldbaum and Patel, 2010). Furthermore, oxidative stress appears to be self-propagating, since cellular macromolecules, damaged by oxidative stress-induced excessive release of ROS, may convert themselves into ROS (Hulbert et al., 2007).

Accumulating evidence suggests that ROS generated via a variety of mechanisms may play complex pathogenetic roles in $\mathrm{AD}$ (Liu et al., 2018). The development of AD is associated with oxidative damage in the brain, including oxidation of nucleic acids, lipids, proteins and carbohydrates (Nunomura et al., 2006). Progressively increasing oxidative stress has been suggested to be an early feature of $\mathrm{AD}$ and a major contributor to the development of the characteristic brain lesions in AD (Harman, 2006; Pimplikar et al., 2010). Oxidative stress may be a result of mitochondrial failure and/or compromised antioxidant capacity with reduced concentrations of endogenous antioxidants. Oxidative events appear to occur before the onset of $A \beta$ accumulation and plaque formation, which lends support to the critical role of oxidative stress in the early stages of AD (Lin and Beal, 2006; Wang et al., 2014). For example, the modulation of JNK/p38 MAPK pathways by oxidative stress leads to $A \beta$ accumulation and tau protein hyperphosphorylation (Patten et al., 2010). The targeting of DNA by ROS is a particular problem in aged brains, since they have been shown to exhibit elevated levels of mitochondrial DNA mutations induced by oxidative stress (Chomyn and Attardi, 2003; Kraytsberg et al.,
2003; Trifunovic et al. 2004). While oxidative stress appears to be an important factor contributing to the initiation and progression of $\mathrm{AD}$, the exact mechanisms involved in the disruption of redox balance and the sources of ROS remain unknown.

Since antioxidants can scavenge reactive radicals and prevent oxidation of substrates at low concentrations (Halliwell and Gutteridge, 1995), they are able to sustain cell integrity and are therefore vital to the defense system of plants, animals and humans. Furthermore, the findings of animal studies suggest that antioxidants may have anti-amyloidogenic effects (Ono et al., 2006). Therefore, the regulation of ROS levels using antioxidants may provide a potential therapeutic approach capable of impeding neurodegeneration in $\mathrm{AD}$.

\section{Natural antioxidants}

Antioxidants have been defined as substances that delay, prevent or remove oxidative damage to a target molecule (Halliwell, 2007). The endogenous antioxidant system in humans, consisting of enzymatic and non-enzymatic antioxidants, is not sufficient to maintain the concentrations of free radicals at low levels and depends on the exogenous supply of various antioxidants through the diet (Pietta, 2000). Most exogenous natural antioxidants are phytochemicals. Major natural antioxidants with potential therapeutic benefits in $\mathrm{AD}$, including vitamins $\mathrm{C}$ and $\mathrm{E}$, carotenoids and flavonoids, may be found in certain foods. Diets rich in fruits and vegetables appear to have protective effects against various diseases and have been reported to be associated with reduced rates of cardiovascular disease and cancer (Cox et al., 2000; Gillman et al., 1995; Joshipura et al., 1999; Strandhagen et al., 2000). Antioxidants are believed to be the primary food bioactives providing the protection afforded by fruits and vegetables (Eastwood, 1999). A review of epidemiological studies concluded that the high content of polyphenolic antioxidants in fruit and vegetables is likely to be the main factor responsible for the health benefits observed (Potter, 1997).

Since antioxidant compounds play an important role in scavenging free radicals, their use has been increasingly promoted as a potential strategy in preventing or reducing neuronal cell death. Exogenous antioxidants have been found to decrease the toxicity of $\beta$-amyloid in the brains of people with AD (Behl, 1997; Christen, 2000). However, little information is available on the efficacy of natural antioxidants in neurodegenerative diseases (Pohl and Kong Thoo Lin, 2018).

In regard to halting neurodegeneration, a variety of natural oxidants have shown promising results in animal models and cell culture studies. For example, dietary polyphenols, including resveratrol, curcumin, catechins and anthocyanins, have been demonstrated to obstruct the initiation and progression of Alzheimer pathology in animals by inhibiting oxidative stress, DNA damage, $\beta$-amyloid aggregation and cell apoptosis in neurocytes (Bastianetto et al., 2007; Darvesh et al., 2010; Mercer et al., 2005). In transgenic mice with an overexpression of $A \beta$, the administration of the polyphenol epigallocatechin-3-gallate from green tea has been found to significantly decrease $A \beta$ deposition, to modulate tau pathology and to reduce $\beta$-amyloid-mediated cognitive impairment (Rezai-Zadeh et al., 2005; Rezai-Zadeh et al., 2008). Furthermore, the administration of ferulic acid protects mice against $A \beta$ peptide toxicity induced by intracerebral injection of $\beta$-amyloid peptide (Yan et al., 2001). Both ferulic acid (Mori et al., 2013) and tannic acid (Mori et al., 2012) markedly decreased AD-like pathology in rats through the inhibition of $\beta$-secretase. 
Furthermore, reduced serum antioxidant levels in humans associated with an increased AD risk may indicate a therapeutic value of their use. For example, a survey conducted in almost 7,000 adults aged 50 years and over found a significantly negative association between the serum concentrations of lycopene and lutein and the risk of $\mathrm{AD}$, which suggests that increased consumption of foods rich in these compounds could decrease the risk (Min and Min 2014).

Flavonoids and related polyphenols from grapes and other fruits have shown free radical scavenging activity and antioxidant and anti-inflammatory effects (Joseph et al. 2005). Flavonoids such as quercetin, anthocyanidins and catechins are all antioxidants that may have preventive effects on the aging of brain functions (Alaei et al., 2015). The best-studied fruit polyphenol, the stilbenoid resveratrol (trans-3,5,4'-trihydroxystilbene), has antioxidant and anti-inflammatory properties. The findings of in vitro and in vivo studies suggest that resveratrol could have potential in the treatment of AD (Lange, 2018b; Lange and $\mathrm{Li}$, 2018). In addition to its antioxidant activities, resveratrol appears to be capable of antagonizing amyloid aggregation, suppressing neuroinflammation, reducing mitochondrial dysfunction, modulating signaling pathways and activating longevity genes such as sirtuins (Calabrese et al., 2008; Crichton et al., 2013; Lange and Li, 2018; Witte et al., 2014). Resveratrol has also been shown in humans to have beneficial effects on glucose control (Bhatt et al., 2002; Brasnyó et al., 2011; Crandall et al., 2012) and blood flow (Kennedy et al., 2010).

Despite a multitude of potential neuroprotective mechanisms related to resveratrol, the translation of the findings in animals to human $\mathrm{AD}$ has so far been impossible. The results of intervention studies of resveratrol in people with mild cognitive impairment or mild to moderate $\mathrm{AD}$ do not provide evidence of neuroprotective or therapeutic efficacy (Köbe et al., 2017; Turner et al., 2015). Limiting factors in the clinical use of resveratrol include its poor solubility and low permeability across the brain blood barrier, and hence its low bioavailability in the brain (Ahmed et al., 2017). Potential benefits of resveratrol and other natural antioxidants AD need to establish a correlation between their bioavailability and biological effects in vivo. Analogs of resveratrol may offer a better therapeutic potential (Kapetanovic et al., 2011; Ma et al., 2014; Pasinetti et al., 2015). For example, the naturally dimethylated analog, pterostilbene (trans-3,5-dimethoxy-4'-hydroxystilbene), has the major advantage of higher in vivo bioavailablity (Estrela et al., 2013). The in vivo effects of pterostilbene found in AD models suggest that this compound may be more effective in combating alterations in the aging brain (Chang et al., 2012). This may be due to the more lipophilic nature of pterostilbene, with its two methoxyl groups, in comparison with the two hydroxyl groups of resveratrol.

The polyphenolic curcumin, a constituent of the spice turmeric, has strong antioxidant, anti-inflammatory and neuroprotective activities (Bhat et al., 2019; Rajeswari, 2006). In particular, curcumin has been demonstrated to reverse neurotoxic and behavorial alterations in animal models of AD (Mendonça da Costa et al., 2019). However, clinical trials have found no benefits of curcumin in AD (Goozee et al., 2016). This may be due to the timing and duration of the interventions or to problems with absorption and bioavailability. Factors limiting the bioactivity of curcumin include chemical instability, water insolubility, lack of potency and selectivity toward target enzymes/genes, limited tissue distribution and extensive metabolism (Nelson et al., 2017). The poor pharmacokinetic and pharmacodynamic properties, the negligible efficacy in various disease models, the presence of a reactive Michael acceptor and toxic effects under certain conditions (Avonto et al., 2011; Burgos-Moron et al. 2010) render curcumin an unlikely can- didate for therapeutic use. The false in vitro and in vivo activities of curcumin have led to its classification as a pan-assay interference compound (Baell and Walters, 2014) and an invalid metabolic panacea compound (Bisson et al., 2016).

In summary, clinical findings demonstrating clinical efficacy of antioxidants in AD are lacking (Barreca et al., 2016).

\section{Natural antioxidants contained in diets}

The failure of specific antioxidants to prevent $\mathrm{AD}$ in intervention studies has led some researchers to adopt a more holistic view of food intake. Emerging evidence suggests that combinations of appropriate antioxidants may have synergistic effects and may be more effective than single compounds (Veurink et al., 2020). A combination of antioxidants has been shown to be effective in decreasing apoptosis and markedly improving learning and memory in transgenic mice (Veurink et al., 2003).

A population-based, prospective cohort study conducted in the Netherlands, comprising 5,395 participants aged $>55$ years with a reliable dietary assessment using a food-frequency questionnaire, showed that a high dietary intake of vitamin $\mathrm{C}$ and vitamin $\mathrm{E}$ was associated with a reduced risk of $\mathrm{AD}$ after a mean follow-up of 6 years; adjustments for a large number of potentially confounding variables were made (Engelhart et al., 2002). It should be noted that consumption of antioxidants contained in food reflects longterm intake. In comparison with supplementation of synthetic compounds, antioxidants from food are consumed simultaneously with other nutrients in a balance that may affect absorption or biological activity (Bronner, 1993).

Prospective studies have reported that high levels of dietary flavonoid intake were associated with a lower risk of AD (Commenges et al., 2000; Engelhart et al., 2002). In a recent prospective, community-based cohort study comprising 921 participants with a mean age of 81.2 years, dietary consumption of flavonols, as assessed using a validated food frequency questionnaire, was negatively associated with incident $\mathrm{AD}$ in models adjusted for age, sex, education, genetic predisposition and participation in cognitive and physical activities (Holland et al., 2020). These results suggest that higher dietary intake of flavonols may be associated with a decreased risk of developing AD. Well-designed trials are required to confirm the clinical relevance of these findings.

The Mediterranean diet contains high concentrations of natural antioxidants, including phenolics, carotenoids, and vitamins $\mathrm{C}$ and E (Scarmeas et al., 2006; Vasto et al., 2012). In epidemiological studies, individuals adhering to a Mediterranean diet have been found to have a reduced risk of cognitive disorders: Higher adherence was associated with a decreased risk of incident cognitive impairment (Tsivgoulis et al., 2013), while lower adherence was related to an elevated incidence of mild cognitive impairment and AD (Gardener et al., 2012). Strict adherence to a Mediterranean diet was associated with a reduction in $\mathrm{AD}$ by $34 \%$ ( $\mathrm{Gu}$ et al., 2010). Healthy, middle-aged individuals who had followed this diet showed less brain atrophy in magnetic resonance imaging and less $\mathrm{A} \beta$ accumulation than those who had not, demonstrating the neuroprotective effects of the Mediterrananean diet (Berti et al., 2018; Mosconi et al., 2018). However, the majority of investigations on the Mediterranean diet and $\mathrm{AD}$ are observational and cannot answer the question whether the association is causal. A confounding factor in these studies is, for example, the interactions between diet and other lifestyle factors, such as physical exercise (Lange, 2018a).

The wide variety of antioxidants contained in the Mediterra- 
nean diet may contribute to a decrease in oxidative stress and the reduced risk of dementia (Dai et al., 2008; Luchsinger et al., 2004; Morris et al., 2002; Paleologos et al., 1998). The Mediterranean diet may also increase plasma concentration of brain-derived neurotrophic factor, which protects neurons against oxidative stress (Sánchez-Villegas et al., 2011). Although the traditional Mediterranean diet is rich in natural antioxidants, other food components of the diet, such as omega-3 polyunsaturated fatty acids from fish and monounsaturated fatty acids from olive oil, may contribute to the beneficial effects in regard to $\mathrm{AD}$ by decreasing or preventing inflammation (Huang et al., 2013). In addition, the reduced risk of $\mathrm{AD}$ associated with the Mediterranean diet could be mediated through a decrease in vascular risk factors and beneficial effects on glucose and lipid metabolism (Biessels et al., 2006; Esposito et al., 2007; Hu et al., 2013; Martínez-González et al., 2008; Panagiotakos et al., 2003; Rumawas et al., 2009; Stampfer et al., 2000).

In summary, diets rich in fruits and vegetables containing cocktails of natural antioxidants are likely to be beneficial in the prevention of AD. However, our knowledge of the quality and quantity of individual food bioactives required for effective neuroprotection is insufficient.

\section{Prooxidant activity of antioxidants}

Even when seemingly natural and healthy food bioactives are supplemented, possible adverse effects need to be considered (Dunn et al., 2010; Klein et al., 2011; Lange et al., 2019d). For example, the administration of antioxidants in high doses has been observed to cause adverse effects (Zadák et al., 2009), possibly due to prooxidative activity. Biological systems have been postulated to require a balance between oxidation and antioxidation, with low amounts of antioxidants being favorable to this system and high doses disrupting the balance (Bouayed and Bohn, 2010).

Prooxidants are substances that induce oxidative stress through the formation of ROS or by inhibiting the antioxidant system. While natural antioxidants are used for their preventive and therapeutic effects, compounds such as polyphenols, flavonoids, carotenoids and anthocyanins, administered at higher doses or under certain conditions, may also act as prooxidants, producing free radicals, causing DNA damage and mutagenesis and aggravating states of disease (Eghbaliferiz and Iranshahi, 2016). The antioxidant-induced reduction in cell damage may boost the occurrence of neoplasia, since the administration of antioxidants may facilitate the survival of genetically damaged cells (Halliwell and Gutteridge, 2015). For example, epidemiological studies have indicated that diets high in carotenoid-rich fruits and vegetables and elevated serum concentrations of $\beta$-carotene are associated with a reduced risk of lung cancer (Mayne, 1996; Peto et al., 1981; Ziegler, 1991). However, an increase in the incidence of lung cancer was observed in heavy smokers receiving $\beta$-carotene supplements for several years (Alpha-tocopherol, beta carotene cancer prevention study group, 1994; Blumberg and Block, 1994; Omenn et al., 1996). The latter finding can probably be attributed to the antioxidant effect on cell proliferation (Khlebnikov et al., 2007).

Factors that can transform the function of an antioxidant into a prooxidant include the presence of metal ions, the redox potential of the antioxidant and its concentration in matrix environments (Gonzalez et al., 2005; Ionescu et al., 1998; Ionescu et al. 2006). The potent antioxidant vitamin $\mathrm{C}$ can act as a prooxidant depending on the dose administered, with antioxidant and proxidant effects following low and high doses, respectively (Seo and
Lee, 2002). The prooxidant effect of vitamin $\mathrm{C}$ is also found when the vitamin is combined with iron or copper (Duarte and Lunec, 2005; Podmore et al., 1998), with the reduced transition metals reducing hydrogen peroxide to hydroxyl radicals through Fenton reaction (Asplund et al. 2002; Urbański and Beresewicz, 2000). Vitamin E ( $\alpha$-tocopherol) is also a potent antioxidant that may become a harmful prooxidant in high concentrations (Carlisle et al. 2000; Blumberg and Block, 1994). In a systematic review and meta-analysis, elevated mortality rates were found following extended supplementation with $\beta$-carotene as well as vitamins $A$ and E (Bjelakovic et al., 2007). Flavonoids have also been shown to act as prooxidants in the presence of transition metals, which catalyze the redox cycling of polyphenols and could lead to the formation of ROS and phenoxyl radicals (Galati and O'Brien, 2004; Halliwell, 2008; Yordi et al., 2012).

Future human studies should clarify the importance of prooxidative activity of phenolics and carotenoids at the doses administered under physiological conditions, since most available findings stem from in vitro experiments using high doses of antioxidants (Wang et al., 2015). Furthermore, the prooxidant activity of polyphenols has been found in the presence of transition metals, such as iron and copper, and the concentrations of these metals in biological systems are lower than those assessed in in vitro studies (Eghbaliferiz and Iranshahi, 2016). Therefore, the possible prooxidant activity of natural antioxidants consumed in foods containing a combination of them may be limited. In addition, prooxidants have been hypothesized to have essential cell signalling properties (Procházková et al., 2011) and other beneficial effects, since a mild degree of oxidative stress could lead to cytoprotection through a prooxidant-induced rise in the levels of antioxidant defenses and xenobiotic-metabolizing enzymes (Halliwell, 2008).

\section{Future directions}

More definitive studies are needed to examine the efficacy of natural antioxidants in AD. Various factors need to be considered in the study design of future investigations. Important aspects are the optimum age for the initiation of antioxidant consumption and the duration of intake. Since the pathogenetic process leading to dementia may begin many years prior to the onset of symptoms, supplementation may have to be initiated in young or middle age. In humans, significant effects would become observable only following decades-long consumption of antioxidants, which would render respective studies unfeasible. Since optimal results of the administration of antioxidants may be expected in early or even presymptomatic stages of $\mathrm{AD}$, the diagnostic identification of subtle neuropathological alterations and biomarkers related to the disease process are required. Furthermore, the tools currently used to assess outcomes may not be able to detect minimal changes in cognitive functions in early stages of AD (Morrison et al., 2013).

The bioavailability of polyphenols is limited; they are poorly absorbed and extensively metabolized, resulting in low serum levels (Bravo, 1998; Cottart et al., 2010; Crozier et al., 2010; Del Rio et al., 2010). The concerns regarding the bioavailability of natural antioxidants stem from studies of the pharmacokinetics of certain agents such as resveratrol. However, the effects of polyphenols could be mediated through the active metabolites of these compounds or through synergistic effects of several polyphenols in juice or fruit extracts (Cottart et al., 2010; Scalbert and Williamson, 2000). Future pharmacokinetic studies need to address the question of the most effective form of antioxidant consumption, 
Table 1. Natural antioxidants in foods and $A D$

\begin{tabular}{|c|c|c|c|c|}
\hline $\begin{array}{l}\text { Natural an- } \\
\text { tioxidants }\end{array}$ & $\begin{array}{l}\text { Foods rich in nat- } \\
\text { ural antioxidant }\end{array}$ & Efficacy in AD models & $\begin{array}{l}\text { Efficacy in clini- } \\
\text { cal trials }\end{array}$ & Comment \\
\hline Vitamin C & $\begin{array}{l}\text { Citrus fruits, } \\
\text { cabbage, rosehip }\end{array}$ & $\begin{array}{l}\text { Decrease in oxidative damage } \\
\text { (Monacelli et al., 2017) }\end{array}$ & $\begin{array}{l}\text { No evidence of } \\
\text { neuroprotective } \\
\text { efficacy (Monacelli } \\
\text { et al., 2017) }\end{array}$ & \multirow{5}{*}{$\begin{array}{l}\text { High dietary intake of vitamins } \\
C \text { and } E \text { associated with reduced } \\
\text { AD prevalence; high-dose } \\
\text { vitamin E supplementation } \\
\text { associated with increased } \\
\text { morbidity and mortality }\end{array}$} \\
\hline Vitamin E & Oils & $\begin{array}{l}\text { Decrease in oxidative damage } \\
\text { (Gugliandolo et al., 2017) }\end{array}$ & Not available & \\
\hline $\begin{array}{l}\text { Epigallocatechin- } \\
\text { 3-gallate }\end{array}$ & Green tea & $\begin{array}{l}\text { Decrease in } A \beta \text { deposition } \\
\text { and cognitive impairment } \\
\text { (Rezai-Zadeh et al., 2008) }\end{array}$ & Not available & \\
\hline Ferulic acid & Fruits, vegetables & $\begin{array}{l}\text { Decrease in AD-like pathology } \\
\text { (Mori et al., 2013) }\end{array}$ & Not available & \\
\hline Tannic acid & Grapes, tea & $\begin{array}{l}\text { Decrease in AD-like pathology } \\
\text { (Mori et al., 2012) }\end{array}$ & Not available & \\
\hline Resveratrol & $\begin{array}{l}\text { Grapes, berries, } \\
\text { grains }\end{array}$ & $\begin{array}{l}\text { Decrease in amyloid deposition } \\
\text { and improved memory functions } \\
\text { (Lange and Li, 2018) }\end{array}$ & $\begin{array}{l}\text { No evidence of } \\
\text { neuroprotective or } \\
\text { therapeutic effects in } \\
\text { mild to moderate AD } \\
\text { (Köbe et al., 2017; } \\
\text { Turner et al., 2015) }\end{array}$ & $\begin{array}{l}\text { Clinical efficacy limited due } \\
\text { to poor bioavailability }\end{array}$ \\
\hline Pterostilbene & Blueberries & $\begin{array}{l}\text { Decrease in } A \beta \text { - induced } \\
\text { neurotoxicity and improved cognitive } \\
\text { functions (Lange and Li, 2018) }\end{array}$ & Not available & $\begin{array}{l}\text { Higher in vivo bioavailablity } \\
\text { and possibly better therapeutic } \\
\text { potential than resveratrol }\end{array}$ \\
\hline Curcumin & Turmeric & $\begin{array}{l}\text { Inhibition of } A \beta \text { - aggregation } \\
\text { (Mendonça da Costa et al., 2019) }\end{array}$ & $\begin{array}{l}\text { No benefits in } \\
\text { clinical trials (Goozee } \\
\text { et al., 2016) }\end{array}$ & $\begin{array}{l}\text { Unlikely therapeutic } \\
\text { potential due to very poor } \\
\text { pharmacokinetics and } \\
\text {-dynamics; possible toxic effects }\end{array}$ \\
\hline
\end{tabular}

Future perspectives: Large-scale clinical trials with long-term exposure to antioxidant-rich diets or (combinations of) natural antioxidants with high bioavailability are required to assess preventive and therapeutic efficacy in $A D$.

i.e. as tablets, extracts, juice or dietary ingredients. In addition, nanotechnology may be able to develop antioxidant bioactives or drugs for the treatment of AD that are able to cross biological barriers and enhance bioavailability (Gao, 2016).

Furthermore, in view of possible toxic effects of curcumin (Burgos-Moron et al., 2010), antioxidant supplements should be considered as medicinal products and should therefore be evaluated extensively in the same way as new drugs prior to marketing.

\section{Conclusion}

Due to its high oxygen consumption and high lipid content, the brain is highly susceptible to oxidative stress. The accumulation of ROS poses a significant threat to neurons. When production of these species exceeds the brain's antioxidant defense capacity, substantial neuronal damage may result. It is well established that oxidative damage of neuronal molecules has a major impact on $\mathrm{AD}$. The pathogenetic role of oxidative stress in $\mathrm{AD}$ has led to the proposal that increased consumption or supplementation of plantderived antioxidants may reduce the development of neuronal dysfunction and may offer preventive or therapeutic potential in AD. Several antioxidants have shown promise in animal models of AD. However, the findings regarding effects of antioxidants in $\mathrm{AD}$ in humans are controversial and inconclusive. Single antioxidants may not suffice in preventing oxidative damage in $\mathrm{AD}$, since a wide variety of endogenous and exogenous antioxidants are involved in the modulation of oxidative stress. Therefore, effects of dietary natural antioxidant cocktails require further investigation regarding the prevention of AD. Furthermore, the use of antioxidants in humans may be hindered by limited bioavailability and insufficient bioactivity in the brain. There is currently no evidence of clinical efficacy of natural antioxidants in people with AD (see Table 1).

While antioxidant scavenging of free radicals may have health benefits, it may also have detrimental effects. Antioxidants, especially when administered in high doses, could disturb the homeostasis associated with the role of ROS in various physiological processes. A controversy surrounding dietary antioxidants concerns their capacity to act as (toxic) prooxidants, depending on their concentration and the presence of other molecules. Antioxidant activity might increase the survival of precursor tumor cells in altered matrix environments and could thus enhance malignancy.

Potential effects of natural antioxidants in the prevention of $\mathrm{AD}$ need to be assessed in studies with long-term exposure to compounds with high bioavailability. Large-scale clinical trials employing sensitive, valid, reliable and ecologically meaningful assessments are needed to establish the therapeutic efficacy of antioxidants. Future studies should employ combinations of antioxidants to maximize bioavailability to different cellular compartments. In addition, the assessment of the effectiveness of antioxidant-rich diets in $\mathrm{AD}$ warrants further investigation. 


\section{References}

Ahmed, T., Javed, S., Javed, S., Tariq, A., Šamec, D., Tejada, S., Nabavi, S.F., Braidy, N., and Nabavi, S.M. (2017). Resveratrol and Alzheimer's disease: Mechanistic insights. Mol. Neurobiol. 54: 2622-2635.

Alaei, H., Siahmard, Z., and Reisi, P. (2015). Red grape juice and Alzheimer's disease. In: Martin, C.R., and Preedy, V.R. (Ed.). Diet and nutrition in dementia and cognitive decline. Elsevier, Amsterdam, pp. 935-942.

Alpha-tocopherol, beta carotene cancer prevention study group. (1994). The effect of vitamin $\mathrm{E}$ and beta carotene on the incidence of lung cancer and other cancers in male smokers. N. Engl. J. Med. 330 1029-1035.

Asplund, K.U., Jansson, P.J., Lindqvist, C., and Nordström, T. (2002). Measurement of ascorbic acid (vitamin C) induced hydroxyl radical generation in household drinking water. Free Radic. Res. 36: 1271-1276.

Avonto, C., Taglialatela-Scafati, O., Pollastro, F., Minassi, A., Di Marzo, V., De Petrocellis, L., and Appendino, G. (2011). An NMR spectroscopic method to identify and classify thiol-trapping agents: Revival of $\mathrm{Mi}$ chael acceptors for drug discovery? Angew. Chem. Int. Ed. Engl. 50: 467-471.

Baell, J., and Walters, M.A. (2014). Chemistry: chemical con artists foil drug discovery. Nature 513: 481-483.

Barreca, D., Bellocco, E., D’Onofrio, G., Nabavi, S.F., Daglia, M., Rastrelli, L., and Nabavi, S.M. (2016). Neuroprotective effects of quercetin from chemistry to medicine. CNS Neurol. Disord. Drug Targets 15 964-975.

Bastianetto, S., Brouillette, J., and Quirion, R. (2007). Neuroprotective effects of natural products: interaction with intracellular kinases, amyloid peptides and a possible role for transthyretin. Neurochem. Res. 32: $1720-1725$

Behl, C. (1997). Amyloid beta-protein toxicity and oxidative stress in Alzheimer disease. Cell Tissue Res. 290: 471-480.

Behl, C., Davis, J.B., Lesley, R., and Schubert, D. (1994). Hydrogen peroxide mediates amyloid $\beta$-protein toxicity. Cell 77: 817-827.

Berti, V., Walters, M., Sterling, J., Quinn, C.G., Logue, M., Andrews, R., Matthews, D.C., Osorio, R.S., Pupi, A., Vallabhajosula, S., Isaacson, R.S., de Leon, M.J., and Mosconi, L. (2018). Mediterranean diet and 3-year Alzheimer brain biomarker changes in middle-aged adults. Neurology 90: e1789-e1798.

Bhat, A., Mahalakshmi, A.M., Ray, B., Tuladhar, S., Hediyal, T.A., Manthiannem, E., Padamati, J., Chandra, R., Chidambaram, S.B., and Sakharkar, M.K. (2019). Benefits of curcumin in brain disorders. BioFactors 45: 666-689.

Bhatt, J.K., Thomas, S., and Nanjan, M.J. (2002). Resveratrol supplementation improves glycemic control in type 2 diabetes mellitus. Nutr. Res. 32: 537-541.

Biessels, G.J., Staekenborg, S., Brunner, E., Brayne, C., and Scheltens, P. (2006). Risk of dementia in diabetes mellitus: a systematic review. Lancet Neurol. 5: 64-74.

Bisson, J., McAlpine, J.B., Friesen, J.B., Chen, S.N., Graham, J., and Pauli, G.F. (2016). Can invalid bioactives undermine natural product-based drug discovery? J. Med. Chem. 59: 1671-1690.

Bjelakovic, G., Nikolova, D., Gluud, L., Simonetti, R., and Gluud, C. (2007). Mortality in randomized trials of antioxidant supplements for primary and secondary prevention: systematic review and meta-analysis. JAMA 8: 842-857.

Blumberg, J., and Block, G. (1994). The alpha-tocopherol beta-carotene cancer prevention in Finland. Nutr. Rev. 52: 242-245.

Bouayed, J., and Bohn, T. (2010). Exogenous antioxidants-Double-edged swords in cellular redox state. Oxid. Med. Cell. Longev. 3: 228-237.

Brasnyó, P., Molnár, G.A., Mohás, M., Markó, L., Laczy, B., Cseh, J., Mikolás, E., Szijártó, I.A., Mérei, A., Halmai, R., Mészáros, L.G., Sümegi, B., and Wittmann, I. (2011). Resveratrol improves insulin sensitivity, reduces oxidative stress and activates the Akt pathway in type 2 diabetic patients. Br. J. Nutr. 106: 383-389.

Bravo, L. (1998). Polyphenols: chemistry, dietary sources, metabolism, and nutritional significance. Nutr. Rev. 56: 317-333.

Bronner, F. (1993). Nutrient bioavailability, with special reference to calcium. J. Nutr. 123: 797-802.

Burgos-Moron, E., Calderon-Montano, J.M., Salvador, J., Robles, A., and
Lopez-Lazaro, M. (2010). The dark side of curcumin. Int. J. Cancer 126: 1771-1775.

Butterfield, D.A., and Lauderback, C.M. (2002). Lipid peroxidation and protein oxidation in Alzheimer's disease brain: potential causes and consequences involving amyloid $\beta$-peptide-associated free radical oxidative stress. Free Radic. Biol. Med. 32: 1050-1060.

Calabrese, V., Cornelius, C., Mancuso, C., Pennisi, G., Calafato, S., Bellia, F., Bates, T.E., Giuffrida Stella, A.M., Schapira, T., Dinkova Kostova, A.T., and Rizzarelli, E. (2008). Cellular stress response: a novel target for chemoprevention and nutritional neuroprotection in aging, neurodegenerative disorders and longevity. Neurochem. Res. 33 2444-2471.

Carlisle, D.L., Pritchard, D.E., Singh, J., Owens, B.M., Blankenship, L.J., Orenstein, J.M., and Patierno, S.R. (2000). Apoptosis and P53 induction in human lung fibroblasts exposed to chromium (VI): effect of ascorbate and tocopherol. Toxicol. Sci. 55: 60-68.

Chang, J., Rimando, A., Pallas, M., Camins, A., Porquet, D., Reeves, J., Shukitt-Hale, B., Smith, M.A., Joseph, J.A., and Casadesus, G. (2012) Low-dose pterostilbene, but not resveratrol, is a potent neuromodulator in aging and Alzheimer's disease. Neurobiol. Aging 33: 20622071.

Chomyn, A., and Attardi, G. (2003). MtDNA mutations in aging and apoptosis. Biochem. Biophys. Res. Commun. 304: 519-529.

Christen, Y. (2000). Oxidative stress and Alzheimer disease. Am. J. Clin. Nutr. 71(Suppl.): 621S-629S.

Commenges, D., Scotet, V., Renaud, S., Jacqmin-Gadda, H., BarbergerGateau, P., and Dartigues, J.F. (2000). Intake of flavonoids and risk of dementia. Eur. J. Epidemiol. 16: 357-363.

Cottart, C.H., Nivet-Antoine, V., Laguillier-Morizot, C., and Beaudeux, J.L. (2010). Resveratrol bioavailability and toxicity in humans. Mol. Nutr. Food Res. 54: 7-16.

Cox, B.D., Whichelow, M.J., and Prevost, A.T. (2000). Seasonal consumption of salad vegetables and fresh fruit in relation to the development of cardiovascular disease and cancer. Publ. Health Nutr. 3: 19-29.

Crandall, J.P., Oram, V., Trandafirescu, G., Reid, M., Kishore, P., Hawkins, M., Cohen, H.W., and Barzilai, N. (2012). Pilot study of resveratrol in older adults with impaired glucose tolerance. J. Gerontol. A Biol. Sci. Med. Sci. 67: 1307-1312.

Crews, L., and Masliah, E. (2010). Molecular mechanisms of neurodegeneration in Alzheimer's disease. Hum. Mol. Genet. 19(R1): R12-R20.

Crichton, G.E., Bryan, J., and Murphy, K.J. (2013). Dietary antioxidants, cognitive function and dementia - a systematic review. Plant Foods Hum. Nutr. 68: 279-292.

Crozier, A., Del Rio, D., and Clifford, M.N. (2010). Bioavailability of dietary flavonoids and phenolic compounds. Mol. Aspects Med. 31: 446467.

Dai, J., Jones, D.P., Goldberg, J., Ziegler, T.R., Bostick, R.M., Wilson, P.W. Manatunga, A.K., Shallenberger, L., Jones, L., and Vaccarino, V. (2008). Association between adherence to the Mediterranean diet and oxidative stress. Am. J. Clin. Nutr. 88: 1364-1370.

Darvesh, A.S., Carroll, R.T., Bishayee, A., Geldenhuys, W.J., and Van der Schyf, C.J. (2010). Oxidative stress and Alzheimer's disease: dietary polyphenols as potential therapeutic agents. Expert Rev. Neurother. 10: 729-745.

Del Rio, D., Borges, G., and Crozier, A. (2010). Berry flavonoids and phenolics: bioavailability and evidence of protective effects. Br. J. Nutr. 104(Suppl. 3): S67-S90.

Dröge, W. (2002). Free radicals in the physiological control of cell function. Physiol. Rev. 82: 47-95.

Duarte, T.L., and Lunec, J. (2005). Review: when is an antioxidant not an antioxidant? A review of novel actions and reactions of vitamin $C$. Free Radic. Res. 39: 671-686.

Dunn, B.K., Richmond, E.S., and Minasian, L.M. (2010). A nutrient approach to prostate cancer prevention: The Selenium and Vitamin Cancer Prevention Trial (SELECT). Nutr. Cancer 62: 896-918.

Eastwood, M.A. (1999). Interaction of dietary antioxidants in vivo: how fruit and vegetables prevent disease? QJM 92: 527-530.

Eghbaliferiz, S., and Iranshahi, M. (2016). Prooxidant activity of polyphenols, flavonoids, anthocyanins and carotenoids: updated review of mechanisms and catalyzing metals. Phytother. Res. 30: 1379-1391.

Engelhart, M.J., Geerlings, M.I., Ruitenberg, A., van Swieten, J.C., Hofman, 
A., Witteman, J.C.M., and Breteler, M.M.B. (2002). Dietary intake of antioxidants and risk of Alzheimer disease. JAMA 287: 3223-3229.

Esposito, K., Ciotola, M., and Giugliano, D. (2007). Mediterranean diet and the metabolic syndrome. Mol. Nutr. Food Res. 51: 1268-1274.

Estrela, J.M., Ortega, A., Mena, S., Rodriguez, M.L., and Asensi, M. (2013). Pterostilbene: biomedical applications. Crit. Rev. Clin. Lab. Sci. 50: 65-78.

Galati, G., and O'Brien, P.J. (2004). Potential toxicity of flavonoids and other dietary phenolics: Significance for their chemopreventive and anticancer properties. Free Radic. Biol. Med. 37: 287-303.

Gao, H. (2016). Progress and perspectives on targeting nanoparticles for brain drug delivery. Acta Pharm. Sin. B. 6(4): 268-286.

Gardener, S., Gu, Y., Rainey-Smith, S.R., Keogh, J.B., Clifton, P.M., Mathieson, S.L., Taddei, K., Mondal, A., Ward, V.K., Scarmeas, N., Barnes, M., Ellis, K.A., Head, R., Masters, C.L., Ames, D., Macaulay, S.L., Rowe, C.C., Szoeke, C., and Martins, R.N. (2012). Adherence to a Mediterranean diet and Alzheimer's disease risk in an Australian population. Transl. Psychiatry 2: e164.

Gillman, M.W., Cupples, L.A., Gagnon, D., Posner, B.M., Ellison, R.C., Castelli, W.P., and Wolf, P.A. (1995). Protective effect of fruits and vegetables on development of stroke in men. JAMA 273: 1113-1117.

Gonzalez, M.J., Miranda-Massari, J.R., Mora, E.M., Guzman, A., Riordan, N.H., Riordan, H.D., Casciari, J.J., Jackson, J.A., and Roman-Franco, A. (2005). Orthomolecular oncology review: ascorbic acid and cancer 25 years later. Integr. Cancer Ther. 4: 32-44.

Goozee, K.E., Shah, T.M., Sohrabi, H.R., Rainey-Smith, S.R., Brown, B., Verdile, G., and Martins, R.N. (2016). Examining the potential clinical value of curcumin in the prevention and diagnosis of Alzheimer's disease. Br. J. Nutr. 115: 449-465.

Gu, Y., Luchsinger, J.A., Stern, Y., and Scarmeas, N. (2010). Mediterranean diet, inflammatory and metabolic biomarkers, and risk of Alzheimer's disease. J. Alzheimers Dis. 22: 483-492.

Gugliandolo, A., Bramanti, P., and Mazzon, E. (2017). Role of vitamin E in the treatment of Alzheimer's disease: evidence from animal models. Int. J. Mol Sci. 18: 2504

Gustafson, D.R., Morris, M.C., Scarmeas, N., Shah, R.C., Sijben, J., Yaffe, K., and Zhu, X. (2015). New perspectives on Alzheimer's disease and nutrition. J. Alzheimer's Dis. 46: 1111-1127.

Halliwell, B. (2007). Biochemistry of oxidative stress. Biochem. Soc. Trans. 35: $1147-1150$

Halliwell, B. (2008). Are polyphenols antioxidants or pro-oxidants? What do we learn from cell culture and in vivo studies? Arch. Biochem. Biophys. 476: 107-112.

Halliwell, B., and Gutteridge, J.M. (1995). The definition and measurement of antioxidants in biological systems. Free Radic. Biol. Med. 18: 125-126.

Halliwell, B., and Gutteridge, J.M.C. (2015). Free radicals in biology and medicine (5th ed). Clarendon Press, Oxford.

Harman, D. (1981). The aging process. Proc. Nat. Acad. Sci. USA 78: 71247128

Harman, D. (2006). Alzheimer's disease pathogenesis: role of aging. Ann. N. Y. Acad. Sci. 1067: 454-460.

Holland, T.M., Agarwal, P., Wang, Y., Leurgans, S.E., Bennett, D.A., Booth, S.L., and Morris, M.C. (2020). Dietary flavonols and risk of Alzheimer dementia. Neurology 94: 1-8.

Hu, N., Yu, J.T., Tan, L., Wang, Y.L., Sun, L., and Tan, L. (2013). Nutrition and the risk of Alzheimer's disease. Biomed. Res. Int. 2013: 524820.

Huang, E.Y., Devkota, S., Moscoso, D., Chang, E.B., and Leone, V.A. (2013). The role of diet in triggering human inflammatory disorders in the modern age. Microbes Infect. 15: 765-774.

Huhn, S., Kharabian Masouleh, S., Stumvoll, M., Villringer, A., and Witte, A.V. (2015). Components of a Mediterranean diet and their impact on cognitive functions in aging. Front. Aging Neurosci. 7: 132.

Hulbert, A.J., Pamplona, R., Buffenstein, R., and Buttemer, W.A. (2007) Life and death: metabolic rate, membrane composition, and life span of animals. Physiol. Rev. 87: 1175-1213.

Ionescu, J.G., Merk, M., and Dowes, F. (1998). Clinical application of redox potential testing in the blood. Syllabus of 33rd AAEM Annual Meeting. Baltimore, USA, pp. 503-512.

Ionescu, J.G., Novotny, J.S., Lätsch, V., Blaurock-Busch, A., and EisenmannKlein, M. (2006). Increased levels of transition metals in breast can- cer tissue. Neuro Endocrinol. Lett. 27(Suppl. 1): 36-39.

Jones, D.P. (2006). Redefining oxidative stress. Antioxid. Redox Signal. 8: 1865-1879.

Joseph, J.A., Shukitt-Hale, B., and Casadesus, G. (2005). Reversing the deleterious effects of aging on neuronal communication and behavior: beneficial properties of fruit polyphenolic compounds. Am. J. Clin Nutr. 81: 313S-316S.

Joshipura, K.J., Ascherio, A., Manson, J.E., Stampfer, M.J., Rimm, E.B., Speizer, F.E., Hennekens, C.H., Spiegelman, D., and Willett, W.C. (1999) Fruit and vegetable intake in relation to risk of ischemic stroke. JAMA 282: 1233-1239.

Kapetanovic, I.M., Muzzio, M., Huang, Z., Thompson, T.N., and McCormick, D.L. (2011). Pharmacokinetics, oral bioavailability, and metabolic profile of resveratrol and its dimethylether analog, pterostilbene, in rats. Cancer Chemother. Pharmacol. 68: 593-601.

Kennedy, D.O., Wightman, E.L., Reay, J.L., Lietz, G., Okello, E.J., Wilde, A., and Haskell, C.F. (2010). Effects of resveratrol on cerebral blood flow variables and cognitive performance in humans: a double-blind, placebo-controlled, crossover investigation. Am. J. Clin. Nutr. 91: 1590-1597.

Khlebnikov, A.I., Schepetkin, I.A., Domina, N.G., Kirpotina, L.N., and Quinn, M.T. (2007). Improved quantitative structure-activity relationship models to predict antioxidant activity of flavonoids in chemical, enzymatic, and cellular systems. Bioorg. Med. Chem. 15: 1749-1770.

Klein, E.A., Thompson Jr, I.M., Tangen, C.M., Crowley, J.J., Lucia, M.S., Goodman, P.J., Minasian, L., Ford, L.G., Parnes, H.L., Gaziano, J.M., Karp, D.D., Lieber, M.M., Walther, P.J., Klotz, L., Parsons, J.K., Chin, J.L., Darke, A.K., Lippman, S.M., Goodman, G.E., Meyskens Jr, F.L., and Baker, L.H. (2011). Vitamin E and the risk of prostate cancer: the Selenium and Vitamin E Cancer Prevention Trial (SELECT). JAMA 306 : 1549-1556.

Köbe, T., Witte, A.V., Schnelle, A., Tesky, V.A., Pantel, J., Schuchardt, J.P., Hahn, A., Bohlken, J., Grittner, U., and Flöel, A. (2017). Impact of resveratrol on glucose control, hippocampal structure and connectivity, and memory performance in patients with mild cognitive impairment. Front. Neurosci. 11: 105

Kraytsberg, Y., Nekhaeva, E., Bodyak, N.B., and Khrapko, K. (2003). Mutation and intracellular clonal expansion of mitochondrial genomes: two synergistic components of the aging process? Mech. Ageing Dev. 124: 49-53.

Lange, K.W. (2018a). Diet, exercise, and mental disorders - public health challenges of the future. Mov. Nutr. Health Dis. 2: 39-59.

Lange, K.W. (2018b). Red wine, resveratrol, and Alzheimer's disease. Mov. Nutr. Health Dis. 2: 31-58.

Lange, K.W., and Li, S. (2018). Resveratrol, pterostilbene and dementia. BioFactors 44: 83-90

Lange, K.W., Guo, J., Kanaya, S., Lange, K.M., Nakamura, Y., and Li, S. (2019a). Mediterranean diet and Alzheimer's disease. Mov. Nutr. Health Dis. 2019 3: 1-15.

Lange, K.W., Guo, J., Kanaya, S., Lange, K.M., Nakamura, Y., and Li, S. (2019b). Medical foods in Alzheimer's disease. Food Sci. Hum. Wellness 8: 1-7.

Lange, K.W., Lange, K.M., Makulska-Gertruda, E., Nakamura, Y., Reissmann, A., Kanaya, S., and Hauser, J. (2017). Ketogenic diets and Alzheimer's disease. Food Sci. Hum. Wellness 6: 1-9.

Lange, K.W., Nakamura, Y., Chen, N., Guo, J., Kanaya, S., Lange, K.M., and $\mathrm{Li}, \mathrm{S}$. (2019c). Diet and medical foods in Parkinson's disease. Food Sci. Hum. Wellness 8: 83-95.

Lange, K.W., Nakamura, Y., Gosslau, A.M., and Li, S. (2019d). Are there serious adverse effects of omega-3 polyunsaturated fatty acid supplements? J. Food Bioact. 7: 1-6.

Lange, K.W., Sahakian, B.J., Quinn, N.P., Marsden, C.D., and Robbins, T.W. (1995). Comparison of executive and visuospatial memory function in Huntington's disease and dementia of the Alzheimer-type matched for degrees of dementia. J. Neurol. Neurosurg. Psychiatry 58: 598-606.

Lin, M.T., and Beal, M.F. (2006). Mitochondrial dysfunction and oxidative stress in neurodegenerative diseases. Nature 443: 787-795.

Liu, Z., Ren, Z., Zhang, J., Chuang, C.-C., Kandaswamy, E., Zhou, T., and Zuo, L. (2018). Role of ROS and nutritional antioxidants in human diseases. Front. Physiol. 9: 477. 
Luchsinger, J.A., Tang, M.X., Siddiqui, M., Shea, S., and Mayeux, R. (2004). Alcohol intake and risk of dementia. J. Am. Geriatr. Soc. 52: 540-546.

Ma, T., Tan, M.S., Yu, J.T., and Tan, L. (2014). Resveratrol as a therapeutic agent for Alzheimer's disease. Biomed. Res. Int. 2014: 350516.

Manach, C., Williamson, G., Morand, C., Scalbert, A., and Rémésy, C. (2005). Bioavailability and bioefficacy of polyphenols in humans. I. Review of 97 bioavailability studies. Am. J. Clin. Nutr. 81: 230S-242S.

Martínez-González, M.A., Fuente-Arrillaga, C., Nunez-Cordoba, J., Basterra-Gortari, F.J., Beunza, J.J., Vazquez, Z., Benito, S., Tortosa, A., and Bes-Rastrollo, M. (2008). Adherence to Mediterranean diet and risk of developing diabetes: prospective cohort study. BMJ 336: 13481351.

Mayne, S.T. (1996). Beta-carotene, carotenoids, and disease prevention in humans. FASEB J. 10: 690-701.

Mendonça da Costa, I., De Moura Freire, M.A., Lopes de Paiva Cavalcanti, J.R., Pessoa de Araújo, D., Norrara, B., Marques Moreira Rosa, I.M., Pereira de Azevedo, E., Meneses do Rego, A.C., Araújo Filho, I., and Pierdoná Guzen, F. (2019). Supplementation with Curcuma longa reverses neurotoxic and behavioral damage in models of Alzheimer's disease: a systematic review. Curr. Neuropharmacol. 17: 406-421.

Mercer, L.D., Kelly, B.L., Horne, M.K., and Beart, P.M. (2005). Dietary polyphenols protect dopamine neurons from oxidative insults and apoptosis: investigations in primary rat mesencephalic cultures. Biochem. Pharmacol. 69: 339-345.

Min, J.Y., and Min, K.B. (2014). Serum lycopene, lutein and zeaxanthin, and the risk of Alzheimer's disease mortality in older adults. Dement. Geriatr. Cogn. Disord. 37: 246-256.

Monacelli, F., Aquarone, E., Giannotti, C., Borghi, R., and Nencioni, A. (2017). Vitamin C, aging and Alzheimer's disease. Nutrients 9: 670.

Mori, T., Koyama, N., Guillot-Sestier, M.-V., Tan, J., and Town, T. (2013). Ferulic acid is a nutraceutical $\beta$-secretase modulator that improves behavioral impairment and Alzheimer-like pathology in transgenic mice. PLoS One 8: e55774.

Mori, T., Rezai-Zadeh, K., Koyama, N., Arendash, G.W., Yamaguchi, H., Kakuda, N., Horikoshi-Sakuraba, Y., Tan, J., and Town, T. (2012). Tannic acid is a natural $\beta$-secretase inhibitor that prevents cognitive impairment and mitigates Alzheimer-like pathology in transgenic mice. J. Biol. Chem. 287: 6912-6927.

Morris, M.C., Evans, D.A., Bienias, J.L., Tangney, C.C., Bennett, D.A., Aggarwal, N., Wilson, R.S., and Scherr, P.A. (2002). Dietary intake of antioxidant nutrients and the risk of incident Alzheimer disease in a biracial community study. JAMA 287: 3230-3237.

Morrison, Y., Wilson, L., Kelly, F., Bennett, C., Duffy, F., McGoldrick, S., and Reynish, E. (2013). Assessment of outcome in clinical trials in mild Alzheimer's disease: urgent time for a rethink? OA Elderly Med. 1: 3 .

Mosconi, L., Walters, M., Sterling, J., Quinn, C., McHugh, P., Andrews, R.E., Matthews, D.C., Ganzer, C., Osorio, R.S., Isaacson, R.S., De Leon, M.J., and Convit, A. (2018). Lifestyle and vascular risk effects on MRIbased biomarkers of Alzheimer's disease: a cross-sectional study of middle-aged adults from the broader New York City area. BMJ Open 8: e019362.

Nelson, K.M., Dahlin, J.L., Bisson, J., Graham, J., Pauli, G.F., and Walters, M.A. (2017). The essential medicinal chemistry of curcumin. J. Med. Chem. 60: 1620-1637.

Nunomura, A., Castellani, R.J., Zhu, X., Moreira, P.I., Perry, G., and Smith, M.A. (2006). Involvement of oxidative stress in Alzheimer disease. J. Neuropathol. Exp. Neurol. 65: 631-641.

Omenn, G.S., Goodman, G.E., Thornquist, M.D., Balmes, J., Cullen, M.R., Glass, A., Keogh, J.P., Meyskens, F.L. Jr., Valanis, B., Williams, J.H., Barnhart, S., and Hammar, S. (1996). Effects of a combination of beta carotene and vitamin A on lung cancer and cardiovascular disease. N. Engl. J. Med. 334: 1150-1155.

Ono, K., Hamaguchi, T., Naiki, H., and Yamada, M. (2006). Anti-amyloidogenic effects of antioxidants: implications for the prevention and therapeutics of Alzheimer's disease. Biochim. Biophys. Acta 1762: 575-586.

Paleologos, M., Cumming, R.G., and Lazarus, R. (1998). Cohort study of vitamin C intake and cognitive impairment. Am. J. Epidemiol. 148: 45-50.

Panagiotakos, D.B., Pitsavos, C.H., Chrysohoou, C., Skoumas, J., Papadimitriou, L., Stefanadis, C., and Toutouzas, P.K. (2003). Status and man- agement of hypertension in Greece: role of the adoption of a Mediterranean diet: the Attica study. J. Hypertens. 21: 1483-1489.

Pasinetti, G.M., Wang, J., Ho, L., Zhao, W., and Dubner, L. (2015). Roles of resveratrol and other grape-derived polyphenols in Alzheimer's disease prevention and treatment. Biochim. Biophys. Acta 1852: 1202-1208.

Patten, D.A., Germain, M., Kelly, M.A., and Slack, R.S. (2010). Reactive oxygen species: stuck in the middle of neurodegeneration. J. Alzheimers Dis. 20(Suppl.2): S357-S367.

Peto, R., Doll, R., Buckley, J.D., and Sporn, M.B. (1981). Can dietary betacarotene materially reduce human cancer rates? Nature 290: 201208.

Pietta, P. (2000). Flavonoids as antioxidants. J. Nat. Prod. 63: 1035-1042.

Pimplikar, S.W., Nixon, R.A., Robakis, N.K., Shen, J., and Tsai, L.H. (2010). Amyloid-independent mechanisms in Alzheimer's disease pathogenesis. J. Neurosci. 30: 14946-14954.

Podmore, I.D., Griffiths, H.R., Herbert, K.E., Mistry, N., Mistry, P., and Lunec, J. (1998). Vitamin C exhibits pro-oxidant properties. Nature 392: 559 .

Pohl, F., and Kong Thoo Lin, P. (2018). The potential use of plant natural products and plant extracts with antioxidant properties for the prevention/treatment of neurodegenerative diseases: in vitro, in vivo and clinical trials. Molecules 23: 3283.

Potter, J.D. (1997). Cancer prevention: epidemiology and experiment. Cancer Lett. 114: 7-9.

Procházková, D., Boušová, I., and Wilhelmová, N. (2011). Antioxidant and prooxidant properties of flavonoids. Fitoterapia 82: 513-523.

Querfurth, H.W., and LaFerla, F.M. (2010). Alzheimer's disease. N. Engl. J. Med. 362: 329-344.

Rajeswari, A. (2006). Curcumin protects mouse brain from oxidative stress caused by 1-methyl-4-phenyl-1,2,3,6-tetrahydro pyridine. Eur. Rev. Med. Pharmacol. Sci. 10: 157-161.

Rezai-Zadeh, K., Arendash, G.W., Hou, H., Fernandez, F., Jensen, M., Runfeldt, M., Shytle, R.D., and Tan, J. (2008). Green tea epigallocatechin3-gallate (EGCG) reduces $\beta$-amyloid mediated cognitive impairment and modulates tau pathology in Alzheimer transgenic mice. Brain Res. 1214: 177-187.

Rezai-Zadeh, K., Shytle, D., Sun, N., Mori, T., Hou, H., Jeanniton, D., Ehrhart, J., Townsend, K., Zeng, J., Morgan, D., Hardy, J., Town, T., and Tan, J. (2005). Green tea epigallocatechin-3-gallate (EGCG) modulates amyloid precursor protein cleavage and reduces cerebral amyloidosis in Alzheimer transgenic mice. J. Neurosci. 25: 8807-8814.

Romero, F.J., Bosch-Morell, F., Romero, M.J., Jareno, E.J., Romero, B., and Marin, N. (1998). Lipid peroxidation products and antioxidants in human disease. Environ. Health Perspect. 106(Suppl. 5): 1229-1234.

Rumawas, M.E., Meigs, J.B., Dwyer, J.T., McKeown, N.M., and Jacques, P.F. (2009). Mediterranean-style dietary pattern, reduced risk of metabolic syndrome traits, and incidence in the Framingham Offspring cohort. Am. J. Clin. Nutr. 90: 1608-1614.

Sánchez-Villegas, A., Galbete, C., Martinez-González, M.A., Martinez, J.A., Razquin, C., Salas-Salvadó, J., Estruch, R., Buil-Cosiales, P., and Martí, A. (2011). The effect of the Mediterranean diet on plasma brainderived neurotrophic factor (BDNF) levels: the PREDIMED-NAVARRA randomized trial. Nutr. Neurosci. 14: 195-201.

Scalbert, A., and Williamson, G. (2000). Dietary intake and bioavailability of polyphenols. J. Nutr. 130: 2073S-2085S.

Scarmeas, N., Stern, Y., Tang, M.X., Mayeux, R., and Luchsinger, J.A. (2006). Mediterranean diet and risk for Alzheimer's disease. Ann. Neurol. 59: 912-921.

Scheltens, P., Blennow, K., Breteler, M.M.B., de Strooper, B., Frisoni, G.B., Salloway, S., and Van der Flieret, W.M. (2016). Alzheimer's disease. Lancet 388: 505-517.

Seo, M.Y., and Lee, S.M. (2002). Protective effect of low dose of ascorbic acid on hepatobiliary function in hepatic ischemia/reperfusion in rats. J. Hepatol. 36: 72-77.

Sies, H. (Ed.). (1985). Oxidative stress. Academic Press, London.

Sohn, E. (2018). A quest to stave off the inevitable. Nature 559: S18-S20.

Stampfer, M.J., Hu, F.B., Manson, J.E., Rimm, E.B., and Willett, W.C. (2000). Primary prevention of coronary heart disease in women through diet and lifestyle. N. Engl. J. Med. 343: 16-22.

Strandhagen, E., Hansson, P.-O., Bosaeus, I., Isaksson, B., and Eriksson, H. 
(2000). High fruit intake may reduce mortality among middle-aged and elderly men. The study of men born in 1913. Eur. J. Clin. Nutr. 54: 337-341.

Trifunovic, A., Wredenberg, A., Falkenberg, M., Spelbrink, J.N., Rovio, A.T., Bruder, C.E., Bohlooly-Y, M., Gidlöf, S., Oldfors, A., Wibom, R., Törnell, J., Jacobs, H.T., and Larsson, N.G. (2004). Premature ageing in mice expressing defective mitochondrial DNA polymerase. Nature 429: 417-423.

Tsivgoulis, G., Judd, S., Letter, A.J., Alexandrov, A.V., Howard, G., Nahab, F., Unverzagt, F.W., Moy, C., Howard, V.J., Kissela, B., and Wadley, V.G. (2013). Adherence to a Mediterranean diet and risk of incident cognitive impairment. Neurology 80: 1684-1692.

Turner, R.S., Thomas, R.G., Craft, S., van Dyck, C.H., Mintzer, J., Reynolds, B.A., Brewer, J.B., Rissman, R.A., Raman, R., and Aisen, P.S. (2015). A randomized, double-blind, placebo-controlled trial of resveratrol for Alzheimer disease. Neurology 85: 1383-1391.

Urbański, N.K., and Beresewicz, A. (2000). Generation of * OH initiated by interaction of $\mathrm{Fe} 2+$ and $\mathrm{Cu}+$ with dioxygen; comparison with the Fenton chemistry. Acta Biochim. Pol. 47: 951-962.

Vasto, S., Rizzo, C., and Caruso, C. (2012). Centenarians and diet: what they eat in the Western part of Sicily. Immunity Ageing 9: 10.

Veurink, G., Liu, D., Taddei, K., Perry, G., Smith, M.A., Robertson, T.A., Hone, E., Groth, D.M., Atwood, C.S., and Martins, R.N. (2003). Reduction of inclusion body pathology in ApoE-deficient mice fed a combination of antioxidants. Free Radic. Biol. Med. 34: 1070-1077.

Veurink, G., Perry, G., and Singh, S.K. (2020). Role of antioxidants and a nutrient rich diet in Alzheimer's disease. Open Biol. 10: 200084.

Waldbaum, S., and Patel, M. (2010). Mitochondrial dysfunction and oxi- dative stress: a contributing link to acquired epilepsy? J. Bioenerg. Biomembr. 42: 449-455.

Wang, D., Wang, Y., Wan, X., Yang, C.S., and Zhang, J. (2015). Green tea polyphenol (-)-epigallocatechin-3-gallate triggered hepatotoxicity in mice: Responses of major antioxidant enzymes and the $\mathrm{Nrf2}$ rescue pathway. Toxicol. Appl. Pharm. 283: 65-74.

Wang, X., Wang, W., Li, L., Perry, G., Lee, H.G., and Zhu, X.W. (2014). Oxidative stress and mitochondrial dysfunction in Alzheimer's disease. Biochim. Biophys. Acta 1842: 1240-1247.

Witte, A.V., Kerti, L., Margulies, D.S., and Flöel, A. (2014). Effects of resveratrol on memory performance, hippocampal functional connectivity, and glucose metabolism in healthy older adults. J. Neurosci. 34: 7862-7870.

Yan, J.J., Cho, J.Y., Kim, H.S., Kim, K.L., Jung, J.S., Huh, S.O., Suh, H.W., Kim, Y.H., and Song, D.K. (2001). Protection against beta-amyloid peptide toxicity in vivo with long-term administration of ferulic acid. Br. J. Pharmacol. 133: 89-96.

Yordi, E.G., Pérez, E.M., Matos, M.J., and Villares, E.U. (2012). Antioxidant and pro-oxidant effects of polyphenolic compounds and structureactivity relationship evidence. In: Bouayed, J., and Bohn, T. (Ed.). Nutrition, Well-Being and Health. IntechOpen.

Yu, B.P. (1994). Cellular defenses against damage from reactive oxygen species. Physiol. Rev. 74: 139-162.

Zadák, Z., Hyspler, R., Tichá, A., Hronek, M., Fikrová, P., Rathouska, J., Hrnciariková, D., and Stetina, R. (2009). Antioxidants and vitamins in clinical conditions. Physiol. Res. 58(Suppl. 1): S13-S17.

Ziegler, R.G. (1991). Vegetables, fruits and carotenoids and the risk of cancer. Am. J. Clin. Nutr. 53: 251S-259S. 